\title{
Carbenoid-mediated nucleophilic "hydrolysis" of 2-(dichloromethylidene)-1,1,3,3-tetramethylindane with DMSO participation, affording access to one-sidedly overcrowded ketone and bromoalkene descendants§
}

\author{
Rudolf Knorr ${ }^{*}$, Thomas Menke, Johannes Freudenreich and Claudio Pires
}

\section{Full Research Paper}

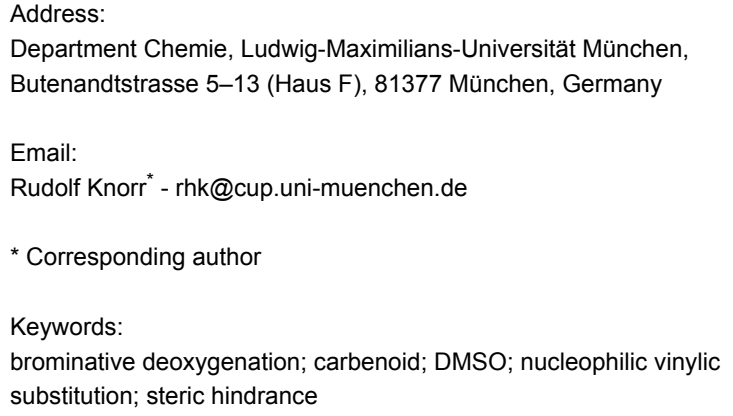

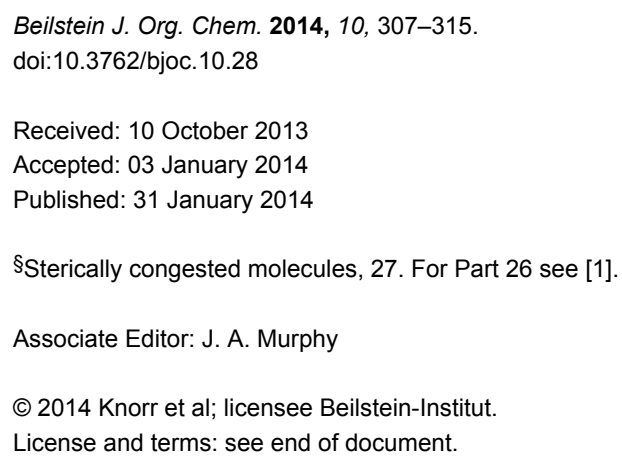

\begin{abstract}
2-(Dichloromethylidene)-1,1,3,3-tetramethylindane was "hydrolyzed" by solid $\mathrm{KOH}$ in DMSO as the solvent at $\geq 100{ }^{\circ} \mathrm{C}$ through an initial chlorine particle transfer to give a $\mathrm{Cl}, \mathrm{K}$-carbenoid. This short-lived intermediate disclosed its occurrence through a reversible proton transfer which competed with an oxygen transfer from DMSO that created dimethyl sulfide. The presumably resultant transitory ketene incorporated $\mathrm{KOH}$ to afford the potassium salt of 1,1,3,3-tetramethylindan-2-carboxylic acid (the product of a formal hydrolysis). The lithium salt of this key acid is able to acylate aryllithium compounds, furnishing one-sidedly overcrowded ketones along with the corresponding tertiary alcohols. The latter side-products (ca. 10\%) were formed against a substantially increasing repulsive resistance, as testified through the diminished rotational mobility of their aryl groups. As a less troublesome further side-product, the dianion of the above key acid was recognized through carboxylation which afforded 1,1,3,3-tetramethylindan-2,2-dicarboxylic acid. Brominative deoxygenation of the ketones furnished two one-sidedly overcrowded bromoalkenes. Some presently relevant properties of the above $\mathrm{Cl}, \mathrm{K}$-carbenoid are provided in Supporting Information File 1.
\end{abstract}

\section{Introduction}

The 1,1,3,3-tetramethylindan-2-yl(idene) fragments shown in the hydrocarbon parts of formulae 4-8 (Scheme 1) are preferable to the corresponding acyclic di-tert-butylmethylidene moiety $\left(t-\mathrm{Bu}_{2} \mathrm{C}\right.$ in $\left.\mathbf{1}-\mathbf{3}\right)$ as the shielding substituent in static and dynamic model systems for several reasons. (i) With respect to repulsive strain, an attempted protonation of the alkoxide $\mathbf{2}$ 
immediately after its generation [2] at $-70{ }^{\circ} \mathrm{C}$ failed to provide 1, because 2 cyclized too rapidly with formation of the chlorooxirane $\mathbf{3}$. On the other hand, the somewhat alleviated internal repulsion in alkoxide $\mathbf{4}$ allowed it to be trapped by protonation below $-10^{\circ} \mathrm{C}$ before the cyclization could interfere [3], so that the resultant alcohol $\mathbf{5}$ could be isolated (crude yield $90 \%$ from 1,1,3,3-tetramethylindan-2-one) and dehydrated to give 2-(dichloromethylidene)-1,1,3,3-tetramethylindane (6) as the only product ( $97 \%$ yield). (ii) In X-ray diffraction analyses [4-9], the 1,1,3,3-tetramethylindan-2-ylidene parts turned out to be rather rigid, except for an occasional folding along the $\mathrm{C}-1 /$ C-3 axis, and they did not exhibit the structural disorder problems and vexing angular flexibility which can arise with the $t-\mathrm{Bu}_{2} \mathrm{C}$ groups exemplified in Scheme 1. (iii) Depending on the substituents at the exocyclic $\mathrm{C}-\alpha$ atom in 7, all four methyl groups in the 1,1,3,3-tetramethylindan-2-ylidene parts [10] and in their truncated analogue 1,1,3,3-tetramethylcyclopent-2ylidene [11] may be nonequivalent and provide useful stereochemical and stereodynamic NMR information that would not be available from models containing the $t-\mathrm{Bu}_{2} \mathrm{C}$ moiety with free rotation about the $t$ - $\mathrm{Bu}-\mathrm{C}$ bonds. (iv) Vinylic nucleophilic substitution $\left(\mathrm{S}_{\mathrm{N}} \mathrm{V}\right)$ of the chloride anion from $\mathbf{6}$ by even a very strong nucleophile $\mathrm{R}-\mathrm{Mt}(\mathrm{Mt}=$ alkali metal $)$ to give 7 may appear problematic, because the first intermediate 9 expected with the usual ARE (addition-rotation-elimination) [12] mechanism would suffer from poor stabilization of the negative charge at $\mathrm{C}-2$ which is flanked by two tert-alkyl groups.

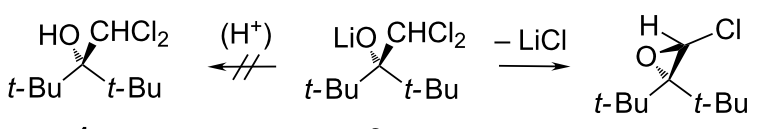

$$
\begin{aligned}
& 1 \\
& 2 \\
& 3
\end{aligned}
$$<smiles>Cc1ccccc1CC(C)(C)C(C)Cl</smiles>

4

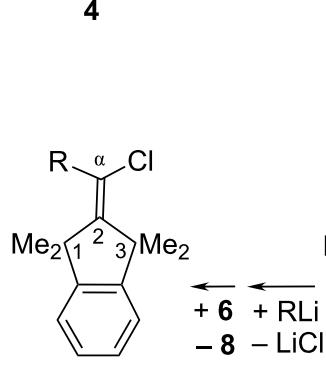

7

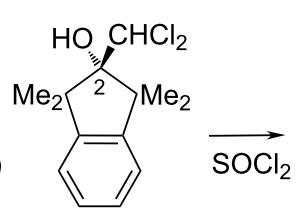

5

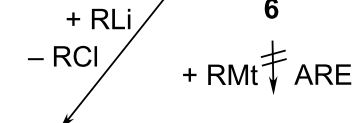

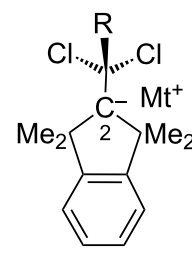

9

Scheme 1: 1,1,3,3-Tetramethylindane derivatives are preferable.

Instead, the substitution products 7 were obtained from $\mathbf{6}$ in THF via the cyclic Li,Cl-carbenoid 8 at room temperature (rt) by the carbenoid chain mechanism [3], as indicated in the bottom line of Scheme 1 . These $\mathrm{S}_{\mathrm{N}} \mathrm{V}$ reactions proceed properly because $\mathbf{8}$ has a reduced (albeit not vanishing) inclination toward cycloalkyne formation through the Fritsch-Buttenberg-Wiechell (FBW) rearrangement [13], whereas $\mathrm{S}_{\mathrm{N}} \mathrm{V}$ reactions of acyclic Mt,Hal-carbenoids often have to compete with FBW processes forming acyclic alkynes.

The $\alpha, \alpha$-dibromo analogue of $\mathbf{6}$ (available [14] from $\mathbf{6}$ in two steps) was found to undergo corresponding but more intricate carbenoid chain reactions. Therefore, it was planned to prepare $\alpha$-bromo analogues of 7 from related ketones which should be accessible via the carboxylic acid $\mathbf{1 0}$ to be expected from a hydrolysis of $\mathbf{6}$.

\section{Results and Discussion "Hydrolysis" of the a,a-dichloroalkene 6}

The carboxylic acid $\mathbf{1 0}$ (Scheme 2) would normally (and more expediently than before [15]) be accessible through a simple hydrolysis reaction $[16,17]$ of 6 with concentrated (80-100\%) sulfuric acid. Our in situ ${ }^{1} \mathrm{H}$ NMR spectra showed that 6 was insoluble in $\mathrm{D}_{2} \mathrm{SO}_{4}(97 \%)$ at $\mathrm{rt}$ and that two promising, equally intense methyl singlet signals, as expected for 10, appeared after seven hours at $100{ }^{\circ} \mathrm{C}$. However, the usual $\left(\mathrm{Et}_{2} \mathrm{O} /\right.$ water $)$ work-up procedure did not afford any (acidic or nonacidic) organic product, which suggests that $\mathbf{6}$ or $\mathbf{1 0}$ were converted to water-soluble, unserviceable arenesulfonic acids that disappeared with the aqueous phases.<smiles>CCC(C(=O)O)C(C)Cc1ccccc1</smiles>

10

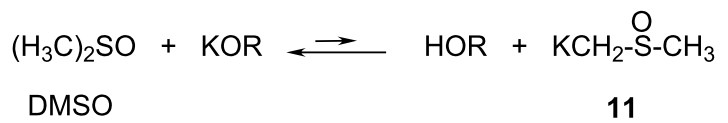

Scheme 2: "Hydrolysis" of 6, and the KOR/dimsyl-K (11) system.

Without electron-withdrawing substituents in both $\mathbf{6}$ and the prospective ARE [12] intermediate 9, several strongly caustic methods of hydrolysis with $\mathrm{KOH}$ failed to consume 6 in diethylene glycol [18] (11 hours at $135^{\circ} \mathrm{C}$ ), in triglyme (six hours, $150^{\circ} \mathrm{C}$ ), in HMPA [tris(dimethylamino)phosphinoxide, five hours at $150{ }^{\circ} \mathrm{C}$ ], and in acetonitrile $\left(23\right.$ hours, $\left.70{ }^{\circ} \mathrm{C}\right)$. 
Reisolation of pure 6 from hot formic acid (44 hours, $90^{\circ} \mathrm{C}$ ) or from dimethyl sulfoxide solution (DMSO, five hours at $156^{\circ} \mathrm{C}$ without a base) showed that $\mathrm{C}-\mathrm{Cl}$ bond heterolysis (vinylic $\mathrm{S}_{\mathrm{N}} 1$ reaction) did not occur in these polar solvents. In DMSO with potassium tert-butoxide $(\mathrm{KO} t$ - $\mathrm{Bu}$, four equiv, $>22$ hours at $140{ }^{\circ} \mathrm{C}$ ) or better with solid $\mathrm{KOH}$ (at least 29 equiv, $\geq$ six hours at $100{ }^{\circ} \mathrm{C}$ or $60 \mathrm{~min}$ at $154{ }^{\circ} \mathrm{C}$ ), however, 6 was slowly transformed into 10. This may be reminiscent of a $10^{9}$-fold increased kinetic basicity $[19,20]$ of $\mathrm{KOCH}_{3}$ in DMSO as a solvent. Due to the strongly enhanced thermodynamic basicity of solid $\mathrm{KOH}$ in DMSO [21-23], this system will provide and maintain a small concentration of the potassium salt 11 of DMSO ("dimsyl-K", Scheme 2). On the other hand, a more special involvement of DMSO as an oxidant in the present "hydrolysis" of 6 became evident when pure dimethyl sulfide $\left(\mathrm{Me}_{2} \mathrm{~S}\right.$, boiling point $37{ }^{\circ} \mathrm{C}$ ) distilled from the reaction vessel into a cold trap during such a preparation of 10. In situ ${ }^{1} \mathrm{H}$ NMR spectra revealed the obligatory formation of ca. one equivalent of $\mathrm{Me}_{2} \mathrm{~S}$ $\left(\delta_{\mathrm{H}}=2.06 \mathrm{ppm}\right)$. Small portions of $\mathrm{Me}_{2} \mathrm{~S}$ stemmed from the slow destruction of DMSO by $\mathbf{1 1}$, as confirmed in a faster run with 11 alone in DMSO during four hours at $150{ }^{\circ} \mathrm{C}$, and presumably also from generation of the side-product potassium formate as formulated further below. Clearly, $\mathrm{Me}_{2} \mathrm{~S}$ could not have been formed from 6 in a simple hydrolytic ARE [12] process with an intermediate such as $\mathbf{9}$ as a precursor of $\mathbf{1 0}$. Instead, we propose a carbenoid pathway in Scheme 3 and justify the specified steps in the sequel.

In a $\mathrm{Cl} / \mathrm{K}$ interchange reaction that generates the $\mathrm{C} 1, \mathrm{~K}$ carbenoid 12, the transfer of a chlorine particle from 6 to $\mathrm{KOH}$ cannot be excluded at the outset in view of the early protocols [24-27] which described the application of dry NaOEt or $\mathrm{KO} t$-Bu at ca. $190{ }^{\circ} \mathrm{C}$ for converting $\operatorname{aryl}_{2} \mathrm{C}=\mathrm{CCl}_{2}$ into $\operatorname{aryl}_{2} \mathrm{CH}-\mathrm{CO}_{2} \mathrm{H}$ along with aryl-C$\equiv \mathrm{C}-$ aryl (the latter in a Fritsch-Buttenberg-Wiechell (FBW) rearrangement [13]). However, dimsyl-K (11) in DMSO without $\mathrm{KOH}$ consumed 6 immediately already at $\mathrm{rt}$, albeit without formation of the acid 10. This suggests $\mathrm{KOH}$ to be essential for creating product 10; it also suggests that $\mathrm{KOH}$ might be a poor competitor of $\mathbf{1 1}$ in a nucleophilic attack on $\mathbf{6}$, perhaps due partially to the low solubility (ca. $0.001 \mathrm{M} \mathrm{[21])} \mathrm{of} \mathrm{KOH}$ in DMSO. Granting preference to the chlorine transfer from 6 to 11, the byproduct 13 of $\mathbf{1 2}$ would hardly be traceable: even if $\mathbf{1 3}$ reacted with $\mathbf{1 1}$, for example, the resultant water-soluble [28] bis(sulfoxide) $\mathbf{1 6}$ might get lost in the usual procedure of aqueous work-up. As an important confirmation of the $\mathrm{Cl}, \mathrm{K}$-carbenoid 12 , however, its conjugated $\mathrm{CH}$-acid 14 [29] was observed during the early period of a running transformation and vanished slowly with regeneration of $\mathbf{1 2}$. This interpretation was corroborated through independent generations of 12 from 14: Using suspensions of $\mathrm{KO} t$ - $\mathrm{Bu}$ as the base in warm THF or cyclohexane for deproto-

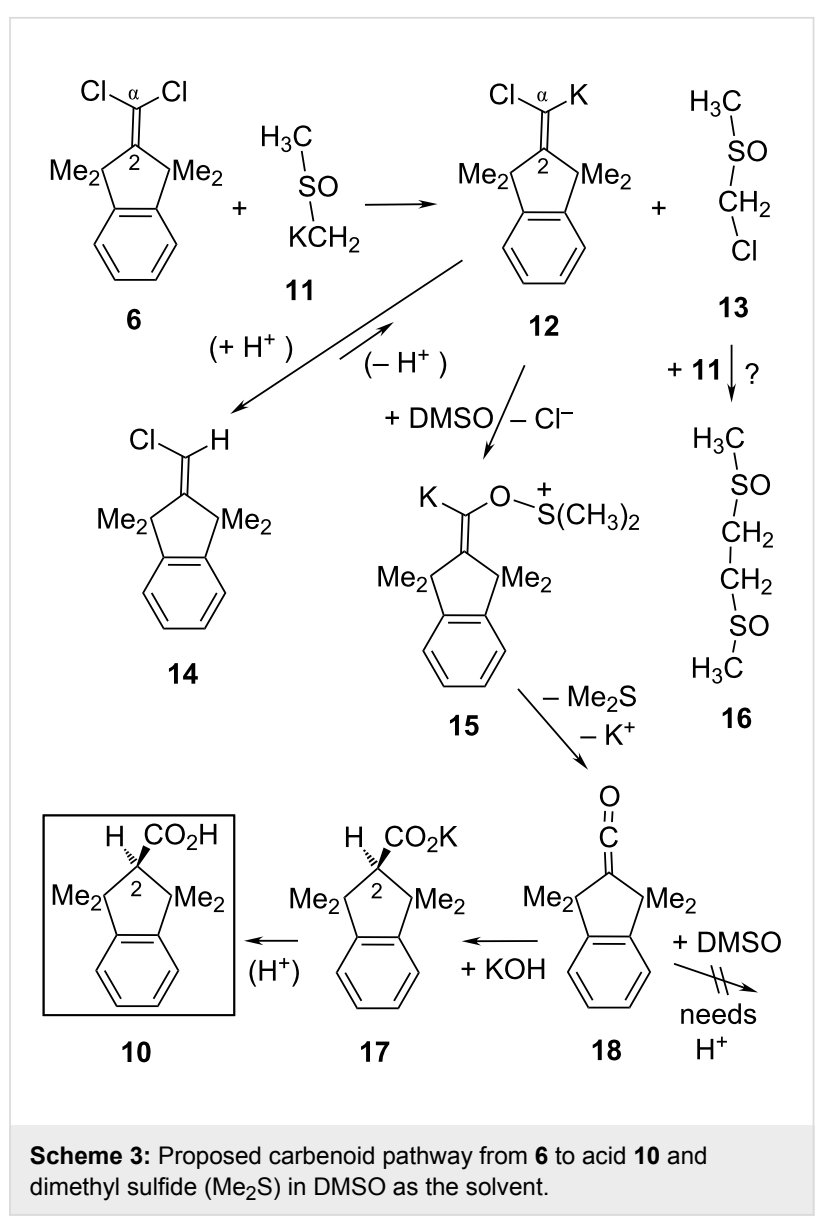

nating 14, the generated 12 was found [30] to undergo expansion (FBW) of its five-membered ring rather than the intended formation of the acid 10. As two demonstrations that FBW ring expansion is not an inevitable fate of bona-fide 12, we deprotonated $\mathbf{1 4}$ also with the freely soluble base $\mathrm{KN}\left(\mathrm{SiMe}_{3}\right)_{2}$ (in place of the hardly soluble $\mathrm{KO} t$ - $\mathrm{Bu}$ ) in $t$-BuOMe or in THF as the solvents and observed [30] in situ merely the nonexpanded enamine (the expected $\mathrm{S}_{\mathrm{N}} \mathrm{V}$ product). Alternatively, we generated 12 from the dichloroalkene $\mathbf{6}$ with a THF solution of benzyl potassium, finding only the carbenoid chain $\left(\mathrm{S}_{\mathrm{N}} \mathrm{V}\right)$ product and its descendants but again no ring expansion [30]. Thus, 12 behaves like a normal unsaturated carbenoid whose $S_{N} V$ reaction requires a more abundant, soluble nucleophile than solid $\mathrm{KO} t$ - $\mathrm{Bu}$ (or, by analogy, solid $\mathrm{KOH}$ ). These observations pointed to a possible $\mathrm{S}_{\mathrm{N}} \mathrm{V}$ reaction of 12 with DMSO and/or dimsyl-K (11), as proposed in Scheme 3 and later on as follows.

In a rapid oxygen-transfer reaction that is known [31,32] for saturated carbenes or carbenoids, 12 will attack the solvent DMSO to generate the K,O-carbenoid $\mathbf{1 5}$ which decays in an E1cb-like expulsion of the observed $\mathrm{Me}_{2} \mathrm{~S}$. The resultant, still unknown di-tert-alkyl ketene $\mathbf{1 8}$ appears to have only limited options in this milieu: Taking $t-\mathrm{Bu}_{2} \mathrm{C}=\mathrm{C}=\mathrm{O}$ [2] as a model of 
the slightly less congested ketene 18, a Pummerer-type acylation of DMSO by $\mathbf{1 8}$ should require the assistance of a carboxylic acid [33]; this is excluded in our strongly basic system. On the other hand, $\mathrm{KOH}$ consumed $t-\mathrm{Bu}_{2} \mathrm{C}=\mathrm{C}=\mathrm{O}$ at $\mathrm{rt}$ readily [34]; thus, the certainly faster addition of $\mathrm{KOH}$ to $\mathbf{1 8}$ can give the observed (in situ ${ }^{1} \mathrm{H}$ NMR) potassium salt $\mathbf{1 7}$ of $\mathbf{1 0}$. Of course, [2-D]17 was detected and [2-D]10 isolated [30] (with ca. $80 \% \mathrm{D}$, for example) from runs of 6 with $\mathrm{KOH}$ in $\left[\mathrm{D}_{6}\right] \mathrm{DMSO}$ due to the H/D interchange reaction affording KOD; a separate experiment established that [2-D]17 was not formed in a subsequent step from unlabeled $\mathbf{1 7}$ with $\mathbf{1 1}$ in $\left[\mathrm{D}_{6}\right] \mathrm{DMSO}$ in the course of 11 hours at $120^{\circ} \mathrm{C}$. In the outlined mechanism, the formal "hydrolysis" of $\mathbf{6}$ to produce the acid $\mathbf{1 0}$ can be seen to consist of an initial reduction of $\mathbf{6}$ generating the carbenoid 12, followed by the oxidation of $\mathbf{1 2}$ by DMSO that affords the precursors of $\mathbf{1 0 .}$

Although the isolated yield of acid $\mathbf{1 0}$ never exceeded $60 \%$, our preparation is convenient because $\mathbf{1 0}$ was obtained as the only acid and in a suitably clean state, expecially when the acidified alkaline layers of aqueous work-up were extracted with pentane (in place of $\mathrm{Et}_{2} \mathrm{O}$ ) which can more efficiently be cleaned from the last traces of DMSO through washing with water. The procedure can also be made colleague-friendly by an early deodorizing of the $\mathrm{Me}_{2} \mathrm{~S}$ contamination through a short treatment of the aqueous solution of $\mathbf{1 7}$ with $\mathrm{NaOCl}$ (but not $\mathrm{KMnO}_{4}$ ), to be terminated soon through the addition of $\mathrm{NaHSO}_{3}$. Gratifyingly, all side-products did not contaminate the acid $\mathbf{1 0}$ because they assembled in the nonacidic fraction as described in the sequel.

The structure of the main side-product 23 (Scheme 4) suggests that it might result from a base-catalyzed condensation of DMSO with 1,1,3,3-tetramethylindan-2-one (24) [35]; this assumption seemed confirmed through the isolation of $\mathbf{2 3}(57 \%)$ from 24 with $\mathrm{KOH}$ (28 equiv) in DMSO after 16 hours at $100{ }^{\circ} \mathrm{C}$. However, the idea that $\mathbf{2 4}$ might have been generated from 6 via 20 (and the dichloro alcohol 5) had to be dismissed: Although an authentic [3] sample of 5 was quickly consumed under the above conditions of hydrolyzing $\mathbf{6}$, it furnished none of $\mathbf{2 4 , 2 3}$ or $\mathbf{1 0}$. Nevertheless, 24 accumulated in the last period of transforming $\mathbf{6}$ into $\mathbf{1 0}\left(>15\right.$ hours at or above $\left.100{ }^{\circ} \mathrm{C}\right)$; such a late appearance of $\mathbf{2 4}$ may be caused by a slowly emerging precursor (other than 5). While $\mathbf{2 4}$ obviously did not hasten to form 23 with DMSO, an alternative route from 6 with $\mathbf{1 1}$ to $\mathbf{2 3}$ appears reasonable: the first intermediate 19 would isomerize to 22 and then dissociate into $\mathrm{KCHCl}_{2}(\mathbf{2 1})$ and product 23 . As a $\mathrm{Cl}, \mathrm{K}$-carbenoid, $\mathbf{2 1}$ will fall a victim to the above-mentioned type of oxygen-transfer reaction [31,32] with DMSO, via 25 for example, to furnish $\mathrm{Me}_{2} \mathrm{~S}$ and potassium formate (26) which was actually detected $\left(\delta_{\mathrm{H}}=8.54 \mathrm{ppm}\right)$ in situ.

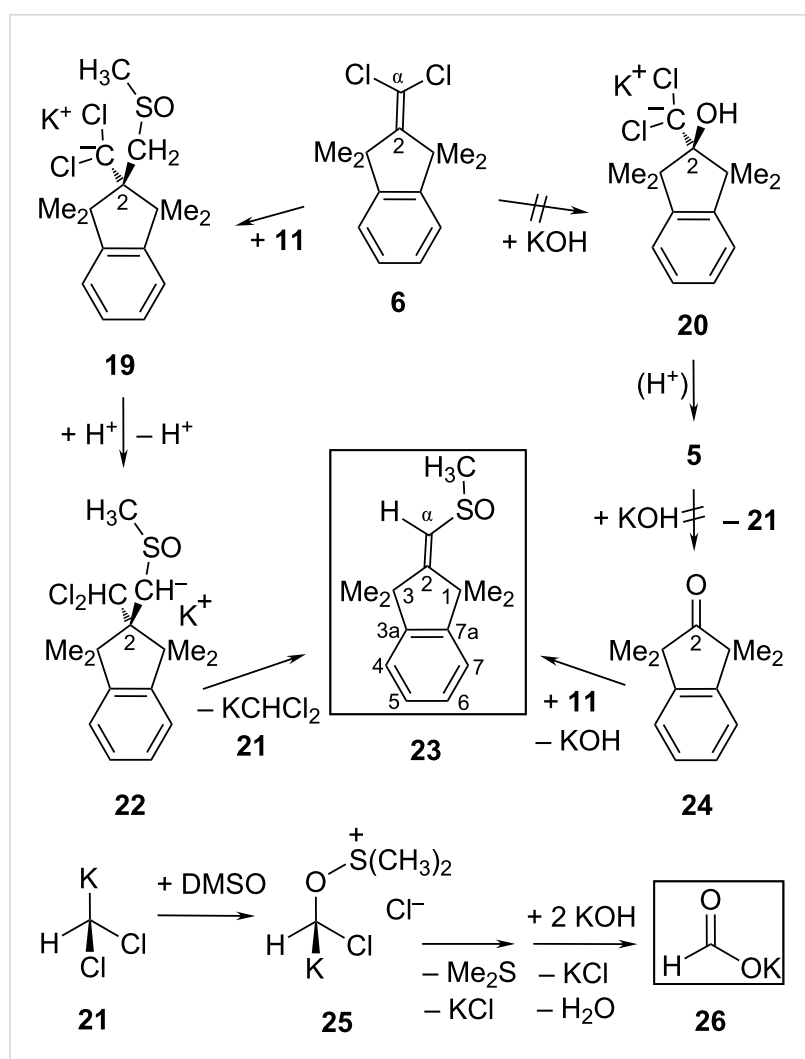

Scheme 4: Proposed pathway to the main side-product $\mathbf{2 3}$ formed by nucleophilic addition of 11 to $\mathrm{C}-2$ of 6 .

The carbenoid chain [3] option has not yet been addressed in the above proposals, because the results outlined in Scheme 3 and Scheme 4 were not compatible with that variant. However, a further side-product $\mathbf{3 3}$ was encountered whose structure may reasonably be explained using the carbenoid chain mechanism in the following manner. As a competitor of the $\mathrm{Me}_{2} \mathrm{~S}-$ producing decay of the K,O-carbenoid 15 to give 18 (Scheme 5), a chlorine particle transfer from 6 to $\mathbf{1 5}$ will close a carbenoid chain cycle and give rise to the chain carrier $\mathbf{1 2}$ together with the primary product $\mathbf{2 8}$. In analogy with the baseinduced $\mathrm{O}-\mathrm{S}$ bond cleavage during the Pummerer acylation with $t-\mathrm{Bu}_{2} \mathrm{C}=\mathrm{C}=\mathrm{O}$ [36], a base-induced decay of $\mathbf{2 8}$ can be expected to generate the 2-thioniapropene 29 along with the $\alpha$-chloroenolate $\mathbf{3 0}$ that may produce the ketene $\mathbf{1 8}$ (or the unknown acyl choride) and finally (as in Scheme 3) the precursor $\mathbf{1 7}$ of acid 10. This alternative route to acid $\mathbf{1 0}$ does not create $\mathrm{Me}_{2} \mathrm{~S}$ and may be a minor contribution, therefore. The expelled cation $\mathbf{2 9}$ may be consumed by the liberated chloride anion to give $\mathrm{H}_{3} \mathrm{C}-\mathrm{S}-\mathrm{CH}_{2} \mathrm{Cl}$ (32) or by dimsyl-K (11) or by formation of $\mathbf{3 3}$ along the following lines (Scheme 5).

In competition with the abundant DMSO to give 15, dimsyl-K (11) may displace a chloride anion from the $\mathrm{Cl}, \mathrm{K}$-carbenoid 12 to generate the vinylpotassium derivative 27. Proton transfer 


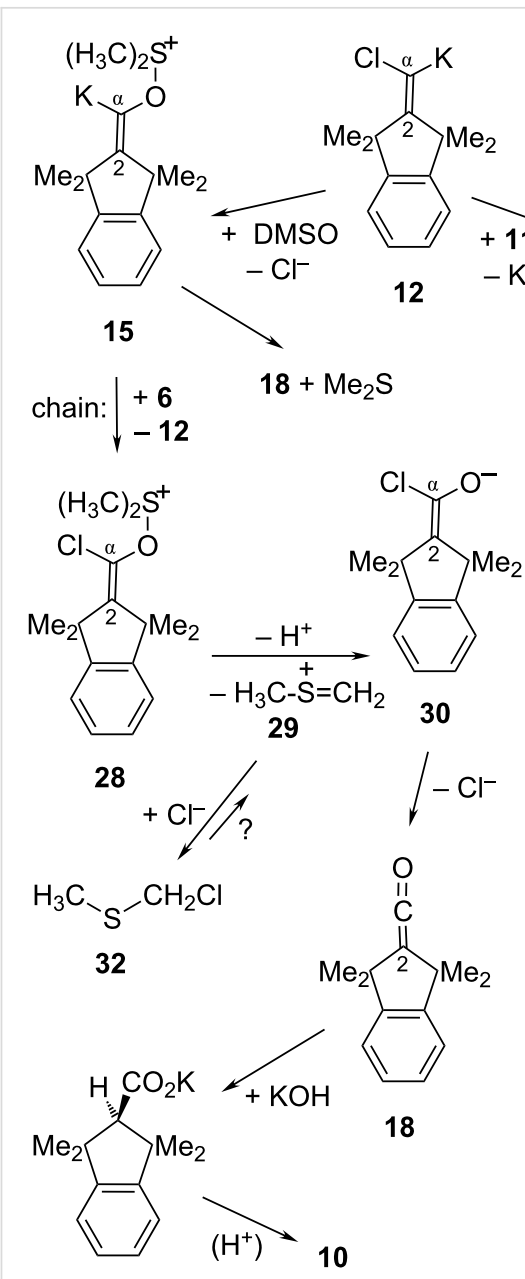

17

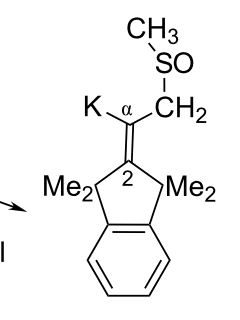

27 $+\mathrm{H}^{+} \downarrow-\mathrm{H}^{+}$

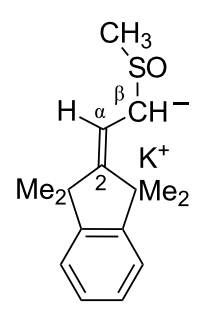

31

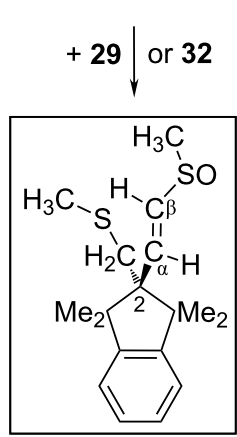

33

Scheme 5: Possible course of the carbenoid chain reaction of 12 with DMSO and the $\alpha$, $\alpha$-dichloroalkene 6 .

steps should isomerize $\mathbf{2 7}$ into the energetically more stable allyl anion derivative $\mathbf{3 1}$. Either $\mathbf{2 9}$ or $\mathbf{3 2}$ may intercept $\mathbf{3 1}$ with formation of the side-product 33, whose structure was recognized through its NMR data [30] as follows. The precursor 31 of 33 cannot have reacted at its $C-\beta$ center, since this would have led to an isomer of $\mathbf{3 3}$ with only one proton-bearing olefinic ${ }^{13} \mathrm{C}$ center $(\mathrm{C}-\alpha)$, whereas two olefinic $\mathrm{CH}$ centers $(\mathrm{C}-\alpha$ and $\mathrm{C}-\beta$ ) were detected in $\mathbf{3 3}$ while its $\mathrm{C}-2$ atom was found to be aliphatic rather than olefinic. Although $\mathbf{3 3}$ is chiral, its only $\mathrm{CH}_{2}$ signal exhibits merely weak line-broadening instead of the expected $\mathrm{AB}$ splitting pattern; this indicated the center of chirality (sulfur) to be rather distant from $\mathrm{CH}_{2}$. The NOESY correlation of this quasi-singlet $\mathrm{CH}_{2}$ signal with the $\mathrm{SCH}_{3}$ resonance established the presence of a $\mathrm{CH}_{2}-\mathrm{S}-\mathrm{CH}_{3}$ instead of a $\mathrm{CH}_{2}-\mathrm{S}(\mathrm{O})-\mathrm{CH}_{3}$ fragment. The $=\mathrm{CH}-\mathrm{S}(\mathrm{O})-\mathrm{CH}_{3}$ group and its proximity to the $\mathrm{CH}_{2}$ protons were recognized through the NOESY correlations of the olefinic $\beta$-proton. This completes the mechanistic considerations for the unusual "hydrolysis"

reaction of the unactivated $\alpha, \alpha$-dichloroalkene $\mathbf{6}$ and its sideproducts.

\section{Toward one-sidedly overcrowded ketone and bromoalkene descendants}

The $\alpha, \alpha$-(di-tert-alkyl)methyl aryl ketones 38 (Scheme 6) would normally be considered to be accessible through Friedel-Crafts acylation of arenes by the acid chloride of $\mathbf{1 0}$. This possibility was repudiated, however, because the similar acyl chloride $t$ - $\mathrm{Bu}_{2} \mathrm{CH}-\mathrm{CO}-\mathrm{Cl}$ did not acylate benzene [37,38]. Instead, the technique [39] of acylating an aryllithium compound such as $\mathbf{3 4}$ by a lithium carboxylate such as $\mathbf{3 6}$ to form $\mathbf{3 5}$ proved effective

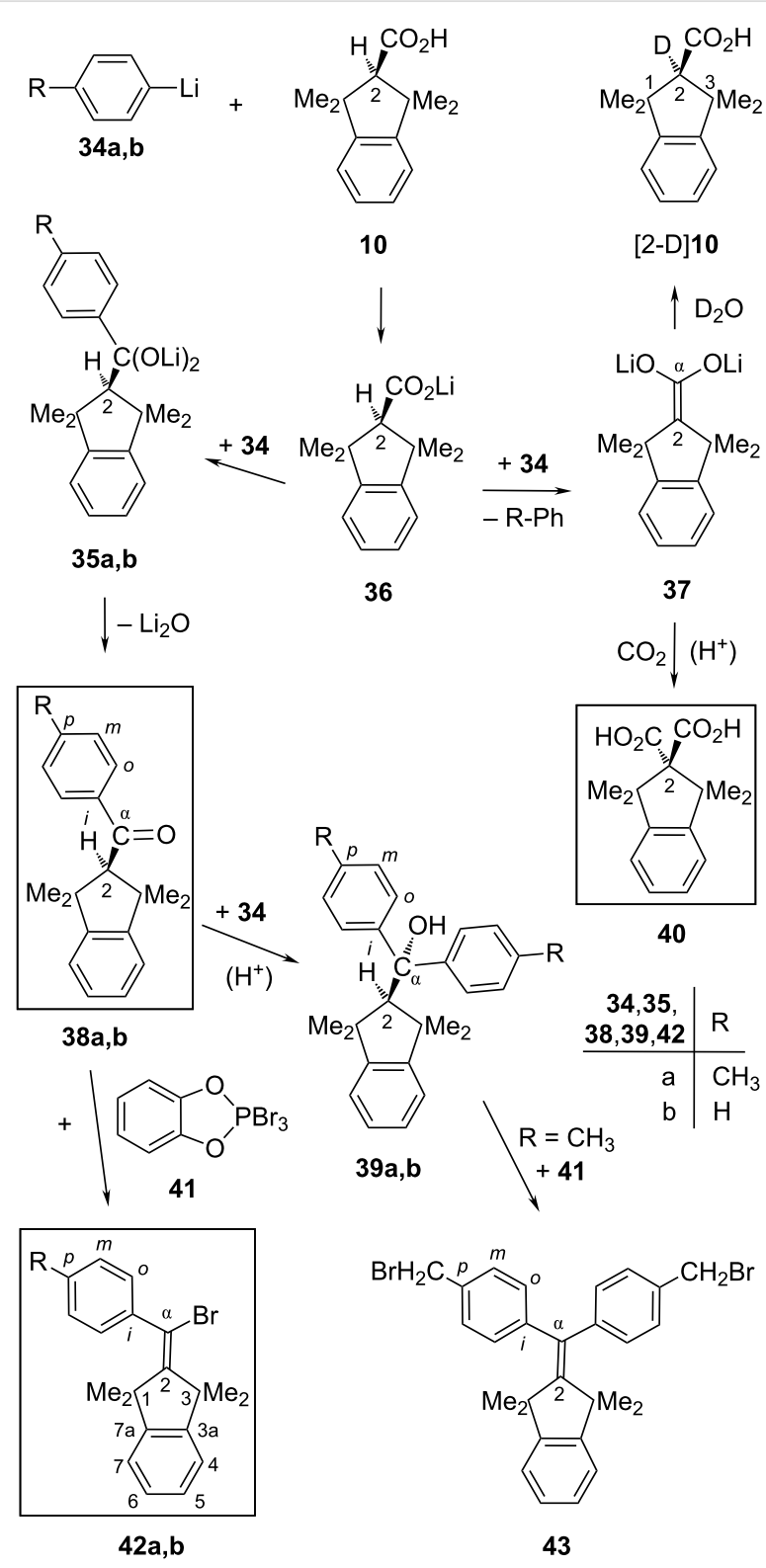

Scheme 6: Synthesis of the one-sidedly overcrowded descendants $\mathbf{3 8}$ 39 , and 42. 
in $\mathrm{Et}_{2} \mathrm{O}$ as the solvent, in spite of a dissuasive message [40] that was based on the failure with 2,6-dimethylbenzoic acid at ice temperature. Admittedly, our protocol requires prolonged stirring in $\mathrm{Et}_{2} \mathrm{O}$ at or above $\mathrm{rt}$ due to steric shielding in 36, which enabled at least two yield-reducing side-reactions to consume the aryllithium reagents $\mathbf{3 4 a}, \mathbf{b}$ to some extent, as delineated below. Therefore, acid $\mathbf{1 0}$ was treated with an excess of $\mathbf{3 4 a}, \mathbf{b}$ which were generated from aryl bromides, using either 2.5 equivalents thereof together with tert-butyllithium $(t-\mathrm{BuLi}$, five equiv) or four equivalents of both aryl bromide and $n$-BuLi. The preformed sodium carboxylate of $\mathbf{1 0}$ in place of $\mathbf{3 6}$ was apparently too insoluble in $\mathrm{Et}_{2} \mathrm{O}$ to react with $\mathbf{3 4}$.

The primary products 35 tend to eliminate $\mathrm{Li}_{2} \mathrm{O}$ slowly with formation of ketones $\mathbf{3 8}$ in the presence of aryllithium reagents 34 which will rapidly add to $\mathbf{3 8}$, creating the tertiary alcohols 39. The unwanted side-products 39 might also arise during simple aqueous work-up where hydrolytic ketone formation from primary products such as $\mathbf{3 5}$ was often [40,41] able to compete with the fast protolysis of residual aryllithium reagents. To avoid this suspected mischief, we applied nonaqueous quenching of residual 34, using either carboxylation by solid $\mathrm{CO}_{2}$ or the commended treatments with aniline [41] as the proton donor or with $\mathrm{Me}_{3} \mathrm{SiCl}$ [40] prior to the aqueous work-up. However, none of these three precautionary measures improved the $\mathbf{3 8} / \mathbf{3 9}$ ratios (ca. 9:1 after ca. 20 hours at rt) significantly, which means that the side-products 39 arose essentially before the work-up procedure. Actually, the unwelcome portions of 39 increased in parallel with extending reaction periods and made especially the isolation of pure ketone 38b somewhat tedious. (An alternative route [30] can provide $\mathbf{3 8} \mathbf{b}$ without side-products.) The overcrowded nature of 39a and 39b became evident [30] through NMR line broadening effects as caused by impeded rotations about the $\mathrm{C}-\alpha / \mathrm{C}$-ipso single bonds.

As a second side-reaction, deprotonation of $2-\mathrm{H}$ in $\mathbf{3 6}$ by $\mathbf{3 4}$ competed with the retarded acylation of $\mathbf{3 4}$, so that the dianion $\mathbf{3 7}$ of acid $\mathbf{1 0}$ was generated and contributed to the recovery of $\mathbf{1 0}$ on aqueous work-up. The intermediacy of $\mathbf{3 7}$ was recognized through quenching either with $\mathrm{D}_{2} \mathrm{O}$ to afford [2-D]10 or with solid $\mathrm{CO}_{2}$ and subsequent isolation of the highly symmetric diacid 40 (only seven ${ }^{13} \mathrm{C}$ NMR signals). The constitution of $\mathbf{4 0}$ followed from its ready decarboxylation in $\mathrm{CDCl}_{3}$ solution at $\mathrm{rt}$ to regenerate acid $\mathbf{1 0}$ within four days.

Conversion of the ketone 38a into bromoalkene 42a through brominative deoxygenation $[42,43]$ with tribromide $\mathbf{4 1}$ was slow in hot chloroform but almost complete within 17 hours at $80{ }^{\circ} \mathrm{C}$ in 1,2-dichloroethane as the solvent. The purification of 42a by simple recrystallization was easy, unless the employed ketone 38a was contaminated with its side-product 39a whose $p$-methyl groups were brominated by reagent $\mathbf{4 1}$ with formation of $\mathbf{4 3}$ [30]. The pure ketone $\mathbf{3 8 b}$ and reagent $\mathbf{4 1}$ furnished the known $[44,45]$ bromoalkene $\mathbf{4 2} \mathbf{b}$ as the only product $[30,46]$.

\section{Conclusion}

The observed features of the "hydrolysis" reaction of the unactivated $\alpha, \alpha$-dichloroalkene 6 with solid KOH in DMSO are incompatible with the key intermediate 9 of the ARE [12] mechanism. Instead, a Cl,K-carbenoid 12 (indicated by the observation of its reversible protonation) is compatible and appropriate as the first intermediate in the route from 6 to acid 10. This formal "hydrolysis" of 6 makes use of the impressively enhanced electrophilicity of "unsaturated" carbenoids [13] such as $\mathbf{1 2}$, which property enables $\mathbf{1 2}$ to react with the moderately nucleophilic but abundant solvent DMSO that brings along the possibility of an oxygen transfer: The necessary cleavage of the $\mathrm{O}-\mathrm{S}$ bond in the resultant $\mathrm{K}$, O-carbenoid 15 may occur either directly (the $\mathrm{Me}_{2} \mathrm{~S}$ producing pathway in Scheme 3) or upon formation of the carbenoid chain product $\mathbf{2 8}$ (Scheme 5). Obviously, DMSO is a unique choice for oxidizing 12 in both the chain and the nonchain mechanistic options. The nonoxidizing nucleophiles $\mathrm{PhCH}_{2} \mathrm{~K}$ and $\mathrm{KN}\left(\mathrm{SiMe}_{3}\right)_{2}$ can convert 12 to the expected nonacidic $\mathrm{S}_{\mathrm{N}} \mathrm{V}$ products, whereas $\mathbf{1 2}$ prefers to expand its five-membered ring if a suitable nucleophile is not available [30].

The easily isolated and purified acid $\mathbf{1 0}$ is able to transfer its bulky di-tert-alkylacetyl body onto a sufficiently reactive nucleophile. The first nucleophilic attack is already sterically impeded, as suggested by its ability to compete with the generation of dianion $\mathbf{3 7}$ of acid $\mathbf{1 0}$ (Scheme 6). Nevertheless, such one-sided shielding in the product ketone does not prevent the incorporation of a second nucleophile, affording a tertiary alcohol with a substantially impeded internal mobility. Final brominative deoxygenation of the ketones can yield bromoalkenes as the only products with moderately decreased speed.

\section{Experimental}

1,1,3,3-Tetramethylindan-2-carboxylic acid (10): The following procedure should be carried out in an efficient hood and/or with a cold trap that can collect and retain malodorant volatile products such as $\mathrm{Me}_{2} \mathrm{~S}$. The dichloroalkene 6 (2.80 g, $11.0 \mathrm{mmol})$, dimethyl sulfoxide $(45 \mathrm{~mL})$, and a magnetic stirring bar were placed in a round-bottomed flask carrying either a wide-bore connection to a cooled trap or a T-shaped glass-tube with a bubbler and gas inlet. This suspension was stirred at $60{ }^{\circ} \mathrm{C}$ until 6 was completely dissolved. Freshly pulverized $\mathrm{KOH}(18.0 \mathrm{~g}, 321 \mathrm{mmol})$ was added and the brown mixture stirred at $100{ }^{\circ} \mathrm{C}$ under inert-gas cover for at least six hours, 
then cooled to rt, poured into distilled water $(250 \mathrm{~mL})$, and shaken with $\mathrm{Et}_{2} \mathrm{O}(3 \times 50 \mathrm{~mL})$. The malodorant aqueous layer containing the potassium salt $\mathbf{1 7}$ was treated batchwise with $\mathrm{NaOCl}$ solution in an amount that sufficed for showing a positive potassium iodide/starch test for $30 \mathrm{~min}$, at which time this residual $\mathrm{NaOCl}$ was forthwith destroyed by solid $\mathrm{NaHSO}_{3}$ that had to be added until the $\mathrm{KI} /$ starch test became negative. $\left(\mathrm{KMnO}_{4}\right.$ in place of $\mathrm{NaOCl}$ was found to decompose 17.) The solution was thoroughly stirred with charcoal, then filtered, cooled in ice, and acidified with concd. hydrochloric acid. The precipitated acid 10 was extracted with $\mathrm{Et}_{2} \mathrm{O}$ or (better) pentane $(3 \times 70 \mathrm{~mL})$. These combined extracts were repeatedly washed with distilled water to remove traces of DMSO, dried over $\mathrm{Na}_{2} \mathrm{SO}_{4}$, and evaporated to leave the almost pure acid $\mathbf{1 0}$ as a white powder $(1.31 \mathrm{~g}, 54 \%)$ with $\mathrm{mp} 188-190{ }^{\circ} \mathrm{C}$ (ref [15]: 189-190.5 $\left.{ }^{\circ} \mathrm{C}\right) ;{ }^{1} \mathrm{H} \mathrm{NMR}\left(\mathrm{CDCl}_{3}, 400 \mathrm{MHz}\right) \delta 1.41$ (s, 6H, 1-/ $3-\mathrm{CH}_{3}$ syn to $\mathrm{CO}_{2} \mathrm{H}$ ), 1.52 (s, $6 \mathrm{H}, 1-/ 3-\mathrm{CH}_{3}$ anti to $\left.\mathrm{CO}_{2} \mathrm{H}\right), 2.91$ (s, 1H, 2-H), $7.16\left(\mathrm{AA}^{\prime}\right.$ part of an $\mathrm{AA}^{\prime} \mathrm{BB}^{\prime}$ system, 2H, 4-/7-H), 7.24 (BB' part, $2 \mathrm{H}, 5-/ 6-\mathrm{H}$ ) ppm, assigned through the NOESY correlations $2-\mathrm{H} \leftrightarrow$ anti- $\mathrm{CH}_{3} \leftrightarrow$ syn- $\mathrm{CH}_{3} \leftrightarrow 4-/ 7-\mathrm{H} \leftrightarrow$ anti$\mathrm{CH}_{3} ;{ }^{1} \mathrm{H}$ NMR ([D $]$ acetone, $\left.400 \mathrm{MHz}\right) \delta 1.35,1.48,2.85,7.12$, $7.18 \mathrm{ppm} ;{ }^{13} \mathrm{C} \mathrm{NMR}\left(\mathrm{CDCl}_{3}, 100.6 \mathrm{MHz}\right) \delta 27.4\left(1-/ 3-\mathrm{CH}_{3}\right.$ syn to $\left.\mathrm{CO}_{2} \mathrm{H}\right), 30.2\left(1-/ 3-\mathrm{CH}_{3}\right.$ anti to $\left.\mathrm{CO}_{2} \mathrm{H}\right), 45.6(\mathrm{C}-1 /-3), 64.8$ (C-2), 122.3 (C-4/-7), 127.3 (C-5/-6), 149.4 (C-3a/7a), 179.1 $\left(\mathrm{CO}_{2} \mathrm{H}\right) \mathrm{ppm}$, assigned through HSQC; ${ }^{13} \mathrm{C}$ NMR $\left(\left[\mathrm{D}_{6}\right]\right.$ acetone, $100.6 \mathrm{MHz}) \delta 27.7,30.5,45.9,65.2,123.1,128.0,150.5,173.4$ ppm.

\section{1,1,3,3-Tetramethyl-2-(methylsulfinylmethylidene)indane}

(23). The combined $\mathrm{Et}_{2} \mathrm{O}$ extracts containing the nonacidic side-products, as obtained in the above preparation of $\mathbf{1 0}$ and separated from the alkaline aqueous layer, were washed with distilled water until neutral, dried over $\mathrm{Na}_{2} \mathrm{SO}_{4}$, and evaporated. The remaining brown solid $(<977 \mathrm{mg}$ ) contained mainly the sulfoxides $\mathbf{2 3}$ and $\mathbf{3 3}$ (3:1) together with a little of 1,1,3,3-tetramethylindan-2-one (24). The pure sample of 23 (284 mg, 10\%) was isolated through extraction into hot, low-boiling petroleum ether $(60 \mathrm{~mL})$, filtration, and concentration. Recrystallization afforded almost colorless needles with mp $134-135{ }^{\circ} \mathrm{C} ;{ }^{1} \mathrm{H}$ $\mathrm{NMR}\left(\mathrm{CDCl}_{3}, 400 \mathrm{MHz}\right) \delta 1.41$ and $1.45(2 \mathrm{~s}, 2 \times 3 \mathrm{H}, 2 \times$ $\left.3-\mathrm{CH}_{3}\right), 1.51$ and $1.73\left(2 \mathrm{~s}, 2 \times 3 \mathrm{H}, 2 \times 1-\mathrm{CH}_{3}\right), 2.67(\mathrm{~s}, 3 \mathrm{H}$, OS- $\left.\mathrm{CH}_{3}\right), 6.25(\mathrm{~s}, 1 \mathrm{H}, \alpha-\mathrm{H}), 7.17\left(\mathrm{AA}^{\prime}\right.$ part of an AA'BB' system, 2H, 4-/7-H), 7.27 (BB' part, 2H, 5-/6-H) ppm, assigned through comparison with the phenylsulfinylmethylidene analogue [47]; ${ }^{1} \mathrm{H}$ NMR (DMSO, $\left.200 \mathrm{MHz}\right) \delta 1.38(2 \times$ $\left.3-\mathrm{CH}_{3}\right), 1.46$ and $1.63\left(2 \times 1-\mathrm{CH}_{3}\right), 6.47(\alpha-\mathrm{H}), 7.24$ (quasi-s, 4-/5-/6-/7-H); ${ }^{13} \mathrm{C} \mathrm{NMR}\left(\mathrm{CDCl}_{3}, 100.6 \mathrm{MHz}\right) \delta 30.12$ and $31.94\left(2 \times 3-\mathrm{CH}_{3}\right), 31.54$ and $32.95\left(2 \times 1-\mathrm{CH}_{3}\right), 40.73$ $\left(\mathrm{OS}-\mathrm{CH}_{3}\right), 48.54(\mathrm{C}-3), 48.76(\mathrm{C}-1), 122.41$ and $122.51(\mathrm{C}-4 /-$ 7), 127.70 and 127.82 (C-5/-6), 128.78 (C- $\alpha$ ), 147.04 (C-3a), $148.23(\mathrm{C}-7 \mathrm{a}), 174.13(\mathrm{C}-2) \mathrm{ppm}$, assigned as above in accord with the deuterium-induced shifts ${ }^{2} \Delta=-0.068$ for $\mathrm{C}-2,{ }^{3} \Delta=$ -0.021 for $\mathrm{C}-3$, and ${ }^{3} \Delta=-0.045$ ppm for $\mathrm{C}-1$ as caused by the $=\mathrm{C}^{\alpha} \mathrm{D}-\mathrm{S}(\mathrm{O})-\mathrm{CD}_{3}$ group incorporated during a run in [D $\mathrm{D}_{6}$ DMSO; IR (KBr) v: 2971, 2959, 2920, 2860, 1627 (w), 1484, 1363, 1032, 1022, 968, 748, 677, $505 \mathrm{~cm}^{-1}$; anal. calcd for $\mathrm{C}_{15} \mathrm{H}_{20} \mathrm{OS}$ (248.39): C, 72.53; H, 8.12; S, 12.91; found: C, $72.75 ; \mathrm{H}, 8.25$; S, 12.94 .

2-(p-Methylbenzoyl)-1,1,3,3-tetramethylindane (38a): A round-bottomed Schlenk flask $(50 \mathrm{~mL})$ was charged with 4-bromotoluene (0.563 mL, $4.58 \mathrm{mmol})$, anhydrous $\mathrm{Et}_{2} \mathrm{O}$ $(10 \mathrm{~mL})$, and a magnetic stirring bar. The contents were stirred and cooled at $-78{ }^{\circ} \mathrm{C}$ under argon gas cover during the dropwise addition of $t$-BuLi $(9.16 \mathrm{mmol})$ in pentane $(6.10 \mathrm{~mL})$, then stirred without cooling for $30 \mathrm{~min}$. After the dropwise addition of acid 10 (400 mg, $1.83 \mathrm{mmol})$ in anhydrous $\mathrm{Et}_{2} \mathrm{O}(10 \mathrm{~mL})$ to this solution of $p$-methylphenyllithium (34a) and further stirring at $\mathrm{rt}$ for 18 hours, the mixture was poured onto solid $\mathrm{CO}_{2}$, warmed up, and diluted with aqueous $\mathrm{NaOH}(1 \mathrm{M}, 20 \mathrm{~mL})$. The aqueous layer was shaken with $\mathrm{Et}_{2} \mathrm{O}(3 \times 20 \mathrm{~mL})$ and the combined four $\mathrm{Et}_{2} \mathrm{O}$ layers were washed with distilled water until neutral, dried over $\mathrm{Na}_{2} \mathrm{SO}_{4}$, and concentrated to leave the crude nonacidic material (455 mg) consisting mainly of $\mathbf{3 8 a}$, 39a, and toluene (9:1:9). Repeated crystallizations from pentane afforded white needles of $\mathbf{3 8 a}$ (isolated yield up to $35 \%$ ); $\mathrm{mp}$ 95.5-96.5 ${ }^{\circ} \mathrm{C}$ (methanol); ${ }^{1} \mathrm{H} \mathrm{NMR}\left(\mathrm{CDCl}_{3}, 400 \mathrm{MHz}\right) \delta 1.34$ and $1.39\left(2 \mathrm{~s}, 2 \times 6 \mathrm{H}, 2 \times 1-/ 3-\mathrm{CH}_{3}\right), 2.42\left(\mathrm{~s}, 3 \mathrm{H}, p-\mathrm{CH}_{3}\right), 4.10$ (s, 1H, 2-H), 7.17 and 7.24 (AA'BB' system, $2 \times 2 \mathrm{H}, 4-/ 5-/ 6-/$ 7-H), 7.28 (broadened d, $\left.{ }^{3} J=8.3 \mathrm{~Hz}, 2 \mathrm{H}, 2 \times m-\mathrm{H}\right), 7.88(\mathrm{dm}$, $\left.{ }^{3} J=8.3 \mathrm{~Hz}, 2 \mathrm{H}, 2 \times o-\mathrm{H}\right) \mathrm{ppm} ;{ }^{1} \mathrm{H} \mathrm{NMR}\left(\mathrm{CCl}_{4}, 80 \mathrm{MHz}\right) \delta$ $1.29,1.35,2.39,3.99,7.06(\mathrm{~s}, 4 \mathrm{H}), 7.18$ (d), $7.80(\mathrm{~d}) \mathrm{ppm} ;{ }^{13} \mathrm{C}$ $\mathrm{NMR}\left(\mathrm{CDCl}_{3}, 100.6 \mathrm{MHz}\right) \delta 21.56\left(p-\mathrm{CH}_{3}\right), 28.02$ and $30.98(2$ $\left.\times 1-/ 3-\mathrm{CH}_{3}\right), 47.17(\mathrm{C}-1 /-3), 64.32(\mathrm{C}-2), 122.34(\mathrm{C}-4 /-7)$, $127.12(\mathrm{C}-5 /-6), 128.28$ and $129.34(2 \times \mathrm{C}-m$ and $2 \times \mathrm{C}-o)$, 138.36 (C-ipso), 143.50 (C-p), 149.99 (C-3a/7a), $201.25(\mathrm{C}=\mathrm{O})$ ppm; IR (KBr) v: 2967, 2925, 2862, 1664 (s), 1606, 1480, 1368, $1228,1209,1186,869,759 \mathrm{~cm}^{-1}$; anal. calcd for $\mathrm{C}_{21} \mathrm{H}_{24} \mathrm{O}$ (292.42): C, 86.26; H, 8.27; found: C, 86.50; H, 8.41.

The above aqueous $\mathrm{NaOH}$ layer was acidified with concd. hydrochloric acid and was shaken with $\mathrm{Et}_{2} \mathrm{O}(3 \times 10 \mathrm{~mL})$. These combined $\mathrm{Et}_{2} \mathrm{O}$ extracts were washed with distilled water until neutral, dried over $\mathrm{Na}_{2} \mathrm{SO}_{4}$, and evaporated to leave a white powder containing acid 10, $p$-methylbenzoic acid, $p$-cresol, and diacid 40 (ca. 4:2:2:1).

1,1,3,3-Tetramethylindan-2,2-dicarboxylic acid (40): The mixture of acids obtained above (see 38a) was leached with pentane, which left the insoluble diacid 40 behind (65 mg, 14\% yield). One recrystallization from hot toluene afforded clean $\mathbf{4 0}$ $(30 \mathrm{mg}$ ) but led to the decarboxylation of a portion that 
remained dissolved. The transparent needles of pure $\mathbf{4 0}$ had a mp of $195-197.5^{\circ} \mathrm{C}$ (dec.), decomposed slowly on standing at rt in $\mathrm{CDCl}_{3}$ solution, and were weakly soluble in $\mathrm{CCl}_{4}$ only as long as they were a part of the original mixture with the other carboxylic acids. ${ }^{1} \mathrm{H}$ NMR $\left(\left[\mathrm{D}_{6}\right]\right.$ acetone or $\left.\mathrm{CDCl}_{3}, 400 \mathrm{MHz}\right) \delta$ $1.58\left(\mathrm{~s}, 12 \mathrm{H}, 2 \times 1-/ 3-\mathrm{CH}_{3}\right.$ ), 7.21 (quasi-s, 4H, 4-/5-/6-/7-H) ppm; ${ }^{13} \mathrm{C}$ NMR $\left(\left[\mathrm{D}_{6}\right]\right.$ acetone, $\left.100.6 \mathrm{MHz}\right) \delta 28.83(2 \times 1-/ 3-$ $\left.\mathrm{CH}_{3}\right), 48.98$ (C-1/-3), 122.28 (C-4/-7), 125.79 (C-2), 127.59 $(\mathrm{C}-5 /-6), 150.30(\mathrm{C}-3 \mathrm{a} / 7 \mathrm{a}), 171.73\left(2 \times \mathrm{CO}_{2} \mathrm{H}\right) \mathrm{ppm}$, assigned through comparison with the acid 10; IR (KBr) v: 3400-2500 (very broad H-O), 1713 (s), 1291, $759 \mathrm{~cm}^{-1}$; anal. calcd for $\mathrm{C}_{15} \mathrm{H}_{18} \mathrm{O}_{4}$ (262.3): C, 68.69; H, 6.92; found: $\mathrm{C}, 69.23$; $\mathrm{H}, 6.81$.

$\mathbf{4 0}$ was not formed from acid $\mathbf{1 0}$ with lithium $N, N$-diisopropylamide in THF as the solvent at $\mathrm{rt}$ : final quenching with solid $\mathrm{CO}_{2}$ afforded only starting material $\mathbf{1 0}$.

2-( $\alpha$-Bromo-p-methylbenzylidene)-1,1,3,3-tetramethylindane (42a): A dry NMR tube ( $5 \mathrm{~mm}$ ) was charged under argon cover gas with 2-bromo-1,3,2-benzodioxaphosphole [48] $(0.12 \mathrm{~mL}, 0.95 \mathrm{mmol})$ and anhydrous, EtOH-free 1,2dichloroethane $(0.5 \mathrm{~mL})$. The solution was cooled in ice, treated with elemental bromine $(0.040 \mathrm{~mL}, 0.78 \mathrm{mmol})$, and kept at $\mathrm{rt}$ for $15 \mathrm{~min}$. This yellow solution of 2,2,2-tribromo-2,2-dihydro1,3,2-benzodioxaphosphole (41) [49] was recooled in ice for the addition of the pure, solid ketone 38a (200 mg, $0.68 \mathrm{mmol}$ ), which caused an immediate color change to brown. The tightly stoppered tube was heated at $80{ }^{\circ} \mathrm{C}$ for at least 17 hours, then diluted with pentane $(5 \mathrm{~mL})$, and poured onto ice-cooled aqueous $\mathrm{Na}_{2} \mathrm{CO}_{3}$ solution $(2 \mathrm{M}, 5 \mathrm{~mL}$ ), which was stirred for 15 min. The aqueous $\mathrm{Na}_{2} \mathrm{CO}_{3}$ layer was shaken with pentane $(2 \times 5 \mathrm{~mL})$ and discarded. The combined pentane extracts were shaken with aqueous $\mathrm{NaOH}(2 \mathrm{M}, 3 \times 5 \mathrm{~mL})$, washed with distilled water $(10 \mathrm{~mL})$, dried over $\mathrm{CaCl}_{2}$, and evaporated to furnish the solid nonacidic fraction $(256 \mathrm{mg}$ ) containing a little residual ketone 38a. Recrystallization from ethanol (12 mL) yielded pure needles of $\mathbf{4 2 a}(173 \mathrm{mg}, 71 \%), \mathrm{mp} 119.5-121^{\circ} \mathrm{C}$; ${ }^{1} \mathrm{H} \mathrm{NMR}\left(\mathrm{CDCl}_{3}, 400 \mathrm{MHz}\right) \delta 1.19\left(\mathrm{~s}, 6 \mathrm{H}, 2 \times 1-\mathrm{CH}_{3}\right), 1.78(\mathrm{~s}$, $\left.6 \mathrm{H}, 2 \times 3-\mathrm{CH}_{3}\right), 2.38\left(\mathrm{~s}, 3 \mathrm{H}, p-\mathrm{CH}_{3}\right), 7.03\left(\mathrm{dm},{ }^{3} \mathrm{~J}=7.5 \mathrm{~Hz}\right.$, $1 \mathrm{H}, 7-\mathrm{H}$ ), 7.16 and 7.22 (quasi-AB system, ${ }^{3} J=8 \mathrm{~Hz}, 2 \times 2 \mathrm{H}, 2$ $\times o-\mathrm{H}$ and $2 \times m-\mathrm{H}$ of tolyl), 7.18-7.27 (m, 3H, 4-/5-/6-H) ppm, assigned through comparison with $\mathbf{4 2 b}[45] ;{ }^{1} \mathrm{H} \mathrm{NMR}\left(\mathrm{CCl}_{4}\right.$, $80 \mathrm{MHz}) \delta 1.17,1.76,2.38,7.14 \mathrm{ppm} ;{ }^{13} \mathrm{C} \mathrm{NMR}\left(\mathrm{CDCl}_{3}\right.$, $100.6 \mathrm{MHz}) \delta 21.30\left(p-\mathrm{CH}_{3}\right), 28.05\left(2 \times 3-\mathrm{CH}_{3}\right), 31.19(2$ $\left.\times 1-\mathrm{CH}_{3}\right), 50.55(\mathrm{C}-1 /-3), 117.95(\mathrm{C}-\alpha), 122.10(\mathrm{C}-4), 122.59$ (C-7), $127.16(\mathrm{C}-5), 127.24(\mathrm{C}-6), 128.53(2 \times \mathrm{C}-m), 129.61(2$ $\times \mathrm{C}-o), 137.66(\mathrm{C}-p), 139.93$ (C-ipso), 149.00 (C-3a), 149.86 (C-7a), 157.11 (C-2) ppm, assigned as above; IR (KBr) v: 2987 , 2959, 2924, 2865, 1505, 1487, 1456, 1363, 799, $757 \mathrm{~cm}^{-1}$; anal. calcd for $\mathrm{C}_{21} \mathrm{H}_{23} \mathrm{Br}$ (355.32): C, 70.99; H, 6.52; Br, 22.49; found: C, 70.88, H, 6.66; $\mathrm{Br}, 23.17$.

\section{Supporting Information}

\section{Supporting Information File 1}

Alternative synthesis of ketone $\mathbf{3 8 b}$; preparation of [2-D]10, 33, 39a, 39b, 42b, and 43; FBW ring expansion of carbenoid 12; $\mathrm{S}_{\mathrm{N}} \mathrm{V}$ reactions of $\mathbf{1 2}$ with $\mathrm{PhCH}_{2} \mathrm{~K}$ and with $\mathrm{KN}\left(\mathrm{SiMe}_{3}\right)_{2}$.

[http://www.beilstein-journals.org/bjoc/content/ supplementary/1860-5397-10-28-S1.pdf]

\section{Acknowledgements}

We are grateful to the Deutsche Forschungsgemeinschaft for generous financial support. This work is dedicated to Professor Manfred Heuschmann in recognition of his unabating consultative support.

\section{References}

1. Knorr, R.; Menke, T.; Ferchland, K. Organometallics 2013, 32 , 468-472. doi:10.1021/om3009348

2. Knorr, R.; Hennig, K.-O.; Schubert, B.; Böhrer, P. Eur. J. Org. Chem. 2010, 6651-6664. doi:10.1002/ejoc.201000888 Compounds 17 and 18 therein.

3. Knorr, R.; Pires, C.; Behringer, C.; Menke, T.; Freudenreich, J.; Rossmann, E. C.; Böhrer, P. J. Am. Chem. Soc. 2006, 128, 14845-14853. doi:10.1021/ja0649116 Compounds 15 and 2c therein.

4. Pilati, T.; Simonetta, M. Acta Crystallogr., Sect. C 1984, 40, 1407-1409. doi:10.1107/S0108270184008131

5. Knorr, R.; von Roman, T.; Nöth, H.; Böck, S. J. Chem. Soc., Perkin Trans. 2 1992, 127-130. doi:10.1039/p29920000127

6. Polborn, K.; Knorr, R.; Böhrer, P. Acta Crystallogr., Sect. C 1992, 48, 490-492. doi:10.1107/S0108270191008466

7. Knorr, R.; Hoang, T. P.; Nöth, H.; Linti, G. Organometallics 1992, 11, 2669-2673. doi:10.1021/om00043a060

8. Knorr, R.; Freudenreich, J.; Polborn, K.; Nöth, H.; Linti, G. Tetrahedron 1994, 50, 5845-5860. doi:10.1016/S0040-4020(01)90440-5

9. Knorr, R.; Menke, T.; Ferchland, K.; Mehlstäubl, J.; Stephenson, D. S. J. Am. Chem. Soc. 2008, 130, 14179-14188. doi:10.1021/ja8026828

10. Knorr, R.; Menke, T.; Behringer, C.; Ferchland, K.; Mehlstäubl, J.; Lattke, E. Organometallics 2013, 32, 4070-4081. doi:10.1021/om4000852 Compound 17 therein.

11. Knorr, R.; Ruhdorfer, J.; Mehlstäubl, J.; Böhrer, P.; Stephenson, D. S. Chem. Ber. 1993, 126, 747-754. doi:10.1002/cber.19931260327 Formulae 15-17 therein.

12. Rappoport, Z. Acc. Chem. Res. 1992, 25, 474-479. doi:10.1021/ar00022a007 And cited literature.

13. Knorr, R. Chem. Rev. 2004, 104, 3795-3850. doi:10.1021/cr030616h

14. Knorr, R.; Pires, C.; Freudenreich, J. J. Org. Chem. 2007, 72, 6084-6090. doi:10.1021/jo070623w Scheme 5 therein. 
15. Knorr, R.; Freudenreich, J.; von Roman, T.; Mehlstäubl, J.; Böhrer, P. Tetrahedron 1993, 49, 8837-8854.

doi:10.1016/S0040-4020(01)81904-9

Compound $\mathbf{4 0}$ therein.

16. Bott, K.; Hellmann, H. Angew. Chem. 1966, 78, 932-936. doi:10.1002/ange.19660782004

Angew. Chem., Int. Ed. Engl. 1966, 5, 870-874. doi:10.1002/anie.196608701

17. Bott, K. Chem. Ber. 1967, 100, 978-983. doi:10.1002/cber.19671000337

18. Grummit, O.; Buck, A.; Egan, R. Org. Syn. Coll. Vol. III 1955, 270-271.

19. Cram, D. J.; Rickborn, B.; Knox, G. R. J. Am. Chem. Soc. 1960, 82, 6412-6413. doi:10.1021/ja01509a055

20. Cram, D. J.; Rickborn, B.; Kingsbury, C. A.; Haberfield, P. J. Am. Chem. Soc. 1961, 83, 3678-3687. doi:10.1021/ja01478a029

21. Dietrich, B.; Lehn, J. M. Tetrahedron Lett. 1973, 14, 1225-1228. doi:10.1016/S0040-4039(01)95803-4

22. Finkentey, C.; Langhals, E.; Langhals, H. Chem. Ber. 1983, 116, 2394-2397. doi:10.1002/cber.19831160631

23. Langhals, E.; Langhals, H. Tetrahedron Lett. 1990, 31, 859-862. doi:10.1016/S0040-4039(00)94647-1 And refs cited therein.

24. Fritsch, P.; Feldmann, F. Justus Liebigs Ann. Chem. 1899, 306, 72-82. doi:10.1002/jlac.18993060106 On $p 79$ therein.

25. Staudinger, H.; Rathsam, G. Helv. Chim. Acta 1922, 5, 645-655. doi:10.1002/hlca.19220050504 On p 654 therein.

26. Harris, E. E.; Frankforter, G. B. J. Am. Chem. Soc. 1926, 48, 3144-3150. doi:10.1021/ja01691a019 On pp 3148-3149 therein.

27. Kaufman, R. J.; Sidhu, R. S. J. Org. Chem. 1982, 47, 4941-4947. doi:10.1021/jo00146a023 Scheme VII therein.

28. Hull, C. M.; Bargar, T. W. J. Org. Chem. 1975, 40, 3152-3154. doi:10.1021/jo00909a037

29. Compound 2 a in ref [3].

30. See the Supporting Information File 1.

31. Oda, R.; Mieno, M.; Hayashi, Y. Tetrahedron Lett. 1967, 8, 2363-2365. doi:10.1016/S0040-4039(00)71607-8

32. Tezuka, Y.; Miya, M.; Hashimoto, A.; Imai, K. J. Chem. Soc., Chem. Commun. 1987, 1642-1643. doi:10.1039/c39870001642

33. Knorr, R. Eur. J. Org. Chem. 2011, 6335-6342. doi:10.1002/ejoc.201100936

34. See $p 6339$ of ref [33].

35. Knorr, R.; Mehlstäubl, J.; Böhrer, P. Chem. Ber. 1989, 122, 1791-1793. doi:10.1002/cber.19891220927 And cited literature.

36. See the Schemes 2, 3, or 5 of ref [33].

37. See Scheme 4 of ref [33].

38. Schaumann, E.; Walter, W. Chem. Ber. 1974, 107, 3562-3573. doi:10.1002/cber.19741071111 Compounds 6 and 9 therein.

39. Jorgensen, M. J. Org. React. 1970, 18, 1-97.

40. Rubottom, G. M.; Kim, C. J. Org. Chem. 1983, 48, 1550-1552. doi:10.1021/jo00157a038

41. Nicodem, D. E.; Marchiori, M. L. P. F. C. J. Org. Chem. 1981, 46, 3928-3929. doi:10.1021/jo00332a040
42. von Roman, U.; Ruhdorfer, J.; Knorr, R. Synthesis 1993, 985-992. doi:10.1055/s-1993-25986

Method A1 therein and quoted literature.

43. Behringer, C.; Knorr, R. J. Prakt. Chem. 1997, 339, 184-186. doi:10.1002/prac.19973390134

44. Knorr, R.; Lattke, E.; Räpple, E. Liebigs Ann. Chem. 1980, 1207-1215. doi:10.1002/jlac.198019800805 Compound 3 therein.

45. Knorr, R.; von Roman, T.; Freudenreich, J.; Hoang, T. P.; Mehlstäubl, J.; Böhrer, P.; Stephenson, D. S.; Huber, H.; Schubert, B. Magn. Reson. Chem. 1993, 31, 557-565.

doi:10.1002/mrc.1260310608 Compound 25 in Table 3 therein.

46. Compound $11 \mathrm{j}$ in ref [42].

47. Compound 18 in ref [45].

48. Compound $5 \mathrm{a}$ in ref [42].

49. Compound $6 \mathbf{a}$ in ref [42].

\section{License and Terms}

This is an Open Access article under the terms of the Creative Commons Attribution License

(http://creativecommons.org/licenses/by/2.0), which permits unrestricted use, distribution, and reproduction in any medium, provided the original work is properly cited.

The license is subject to the Beilstein Journal of Organic Chemistry terms and conditions:

(http://www.beilstein-journals.org/bjoc)

The definitive version of this article is the electronic one which can be found at: doi: $10.3762 /$ bjoc. 10.28 